\title{
Telecommuting and residential locational preferences: a case study of the Netherlands
}

\author{
Saim Muhammad • Henk F. L. Ottens • Dick Ettema • \\ Tom de Jong
}

Received: 1 October 2006 / Accepted: 1 July 2007 / Published online: 7 September 2007

(C) Springer Science+Business Media B.V. 2007

\begin{abstract}
Traditionally, along with stages of the life cycle and changes in people's financial status and their household composition, the commute distance has been identified as one of the main explanatory factors for residential locational preferences and subsequent migration flows. In the Netherlands, telecommuting is rapidly becoming popular and is expected to affect residential locational preferences. A hypothesis that can be raised is that telecommuting has an impact on the effect that commute distance has on residential preferences. Based on this hypothesis, this paper investigates the role of telecommuting alongside the traditional factors currently explaining residential locational preferences. The paper provides evidence that, in the Netherlands, telecommuting has enabled people to commute longer distances. The effect of telecommuting on the probability of relocating, however, is not significant. Telecommuting appears to have a limited effect on residential location preferences, but traditional factors, such as life cycle stages, remain the dominant explanatory factors.
\end{abstract}

Keywords Commuting $\cdot$ Telecommuting $\cdot$ Commute distance $\cdot$ Residential preferences

\section{Introduction}

During the last three decades, in particular since 1995, Information and Communication Technologies (ICTs) have evolved to a level that enables people to access opportunities

\footnotetext{
S. Muhammad $(\bowtie) \cdot$ H. F. L. Ottens · D. Ettema · T. de Jong

Urban and Regional Research Centre Utrecht (URU), Faculty of Geosciences, Utrecht University, Heidelberglaan 2, P.O. Box 80.115, 3508TC Utrecht, The Netherlands

e-mail: s.muhammad@geo.uu.nl

H. F. L. Ottens

e-mail: h.ottens@geo.uu.nl

D. Ettema

e-mail: d.ettema@geo.uu.nl

T. de Jong

e-mail: t.deJong@geo.uu.nl
} 
such as work (telecommuting), shopping (teleshopping), and education (e-learning) in virtual space, complementing the traditional access in physical space. Hence, a hybrid space has emerged as a mode for spatial activities. This is part of a general trend in the postindustrial society, where human activities have become increasingly person-based in the sense that a growing number of them are no longer firmly linked to fixed geographic locations (Couclelis 1998). ICTs have strengthened this trend by offering opportunities on networked personal computers, notebooks, and other mobile devices. As a consequence, people can now access opportunities in virtual space without facing the friction of spatial separation (distance). Based on this paradigmatic shift in the meaning of distance, different schools of thought have developed regarding the impact of ICTs on spatial development. Some examples are the "death of distance" by Cairncross (1998), the "rise of the new place" by Malecki and Gorman (2001) and Wilson et al. (2001), "feed off and fuel" by Graham and Marvin (2000) and "an old script replayed with new actors" by Mitchell (2000). Thus, the effects of ICTs on human spatial activities and resulting spatial structures are still the subject of academic discussion. Consequently predictions are diverse, particularly with respect to future urbanization trends (Couclelis 2003).

In the context of the spatial organization of work, the ICT revolution has had a strong impact on opportunities to work in places other than the employer's premises. The term telecommuting was first used by Nilles in 1973 to refer to "the partial or total substitution of telecommunications with or without the assistance of computers for the daily commute to work" (Mokhtarian 1991). Telecommuting is in fact a special form of teleworking. Teleworking is a broad term defined as "substitutions of all work-related travel by telecommunication and related information technologies" (Nilles 1988).

The rapid development and use of ICTs has had a strong impact on the number of people telecommuting, which has increased markedly in the last few decades (Bates and Huws 2001; CBS 2005; Huws and O'Regan 2001; Johnston and Nolan 2002; TWF 2004). In the Netherlands in 1995, the share of all jobs that were fully telecommuted with a formal contract was $2.3 \%$ and another $6.3 \%$ were mobile, with travelling workers using telecommunication for their occupation. In the year 2000, the share of all jobs in the Netherlands that were being telecommuted from home had risen to $6 \%$, with a further $6 \%$ mobile telecommuted, of which $3 \%$ by self-employed people (Willigenburg and Van Osch 2000).

Comparative international statistics indicate that the Netherlands is a forerunner. In the year 2002, $9 \%$ of the total employed population telecommuted for more than one full day per week, while for the European Union this percentage was 2 and for the USA 5. In 2005, these percentages were 21,7 , and 17 respectively (Todd 2006). International statistics also reveal that in the Netherlands $45 \%$ of all jobs are suited for telecommuting, with $31 \%$ for the EU and $37 \%$ for the USA (Empirica 2003). This large percentage is caused by the strong services orientation of the Dutch economy.

Traditionally, along with other socioeconomic, demographic and environmental factors, job accessibility in terms of commuting distance in physical space has been important in understanding residential location choices in the Netherlands (Van Ommeren et al. 2000; Van Ommeren et al. 1997). This relationship can be understood from the preference of workers to limit their commuting distance and time (Horner 2004). Since, in the case of telecommuting, physical commuting trips are made less frequently, a longer commuting distance may be less problematic. Thus, the opportunity to telecommute may affect a telecommuter's perception and evaluation of distance, and thereby the residential location priorities and decisions (Mokhtarian et al. 2003). Hence, with the mentioned growth of telecommuting and other activities in virtual space, locational preferences for different 
types of residential environment are expected to change in a sense that different trade-offs are made between commuting time and characteristics of the dwelling and its amenities. In general terms, telecommuters will have a spatially wider range of options than traditional physical commuters. It can therefore be expected that commuters and telecommuters will have different residential locational preferences.

In order to understand the trends in urbanization dynamics in an ICT-based society, it is necessary to investigate the geographical residential preferences of both commuters and telecommuters, as well as the factors affecting these preferences. This paper investigates the role of telecommuting alongside the traditional factors responsible for residential locational preferences. Although it is too early to come up with definitive answers, first indications can be found in large-scale housing surveys, especially in countries that already have a sizeable share of telecommuters. To that end, this paper presents the outcomes of analyses based on the official Netherlands' housing demand survey (Woning Behoefte Onderzoek (WBO) 2002).

In order to investigate the impact of telecommuting on residential location preferences, a series of hypotheses are developed and will be tested. Following Van Reisen (1997) and Mokhtarian et al. (2003), we hypothesize that the lower commute frequency, made possible by telecommuting, allows workers to accept longer commute distances. Therefore, we expect commute distances of telecommuters to be longer than those of regular commuters. In addition, since longer commute distances will be acceptable, telecommuters have better opportunities to live in suburban or rural areas that are further away from employment centres. Consequently we expect that their current and desired residential areas are more likely to be suburban or rural. Finally, the question is to what extent the decision to telecommute is made jointly with the location decision or afterwards. In the first case, telecommuting is a permanent status that is deliberately chosen to accommodate living in a suburban or rural area. Telecommuters would then be equally likely to relocate as regular commuters. In the second case, telecommuting is seen as a temporary measure to deal with an undesired long commute. Telecommuters would then be more likely to relocate in order to have a shorter commute distance. In this paper, we hypothesize that the first case holds, implying that the telecommuting decision is made in connection with the relocation decision.

To test the above hypotheses, the paper is structured as follows. First, the major determinants of residential location preferences are discussed and the selected methods for statistical research are described. We then report our exploration of whether telecommuting played any part in the selection of the location of the current residence. Next, the analysis of whether telecommuting affects the commuting distance is reported. Moreover, along with other traditional factors, the relationship between telecommuting and intentions to move in the near future is analysed. Finally, it is explored whether telecommuting will have an influence on future residential location preferences. The article concludes with a discussion of the results.

\section{Residential locational preferences}

In general, it is assumed that residential locational preferences are influenced by housing characteristics such as cost, size, and amenities and by the socioeconomic characteristics of the occupants, such as age, income, gender, and household composition (Renkow and Hoover 2000). According to Nijkamp et al. (1993), the life course rather than economic motives is the predominant factor in residential relocation decisions. Needs and values 
change over the life course and these changes are presumably reflected in changes of residential priorities (Dokmeci and Berkoz 2000; Sirgy et al. 2005). Along with those changes, mobility decreases with increasing age. Middle-aged households are less likely to move than younger households, and the elderly are the least prone to relocate (Michaelson 1977).

In empirical research, life cycle stages have consistently been found to correlate with locational preferences (Hansen 1959; Lamanna 1964). Lindberg et al. (1992), Clark and Onaka (1983) and Speare et al. (1975) have shed light on the relationship between reasons for moving and age. They found that housing type and size adjustment according to the composition of the household largely explain mobility over all age groups. Young couples with small households need smaller houses than older couples with more children, and the elderly with shrunken households move to smaller houses. Along with these socio-demographic characteristics, the economic status of the household and the amenities of the dwelling are also important determinants in the relocation decision. For young people, whether married or not, housing costs and tenure are important factors in deciding where to live. For those in the midlife stage, tenure, housing unit size, and housing quality are the most important determinants (Hansen 1959). Children in the household also have an effect on residential location choice. People in the childrearing stage trade-off the quality of the residential environment against job accessibility (Kim et al. 2005).

A second set of factors is related to the interrelation between residential and workplace location decisions of workers. The outcome of the two decisions determines workers' commuting pattern (Horner 2004; Naes 2005; Simpson 1987; Van der Laan et al. 2005; Van Ommeren et al. 2000). For example, a job change or move can make the new homeworkplace combination sub-optimal, meaning that either a new move or a new job location is needed in the medium to long term (Horner 2004).

Telecommuting, either working from home or at a telecentre, can change the role of the commuting distance. For the Netherlands, Van Reisen (1997) found an average commute distance of 38 kilometres for telecommuters while in 1995, the average commuting distance in the Netherlands for regular commuters was $21 \mathrm{~km}$ (CBS 1995). Mokhtarian and Salomon (1997), Mokhtarian and Varma (1998) and Giuliano (1998) also show that commuting distances are larger for telecommuters than for regular commuters. Thus, telecommuting facilitates longer commuting distances in physical space with a lower commuting frequency than regular commuters (Ellen and Hempsted 2002). This increased commuting distance for telecommuters is expected to change the interrelation between the locations of workplace and residence. Thus, for telecommuters who wish to avoid the high costs and other perceived drawbacks of urban living, moving to more peripheral, low-density residential environments becomes an option (Mokhtarian 1998; Raspe and Oort 2004).

Although socioeconomic, demographic, and environmental characteristics still largely determine residential locational preferences (Kim et al. 2005), this may change as a result of recent socioeconomic changes caused by ICTs, especially the use of ICTs for telecommuting (Castells and Hall 1994; Johnston et al. 1994; Mohammad et al. 2003; Van Oort et al. 2003b).

The Netherlands is a densely populated country with a relatively compact but decentralized urbanization pattern. Although spatial planning has had a relatively powerful influence on urban development, in the last few decades, housing prices have increased considerably. Moreover, spatial policies were recently decentralized and relaxed, increasing the influence of market forces (Healy 2004). The mass adoption of ICTs, which relaxes spatial binding, is assumed to increase the desire to have relatively less expensive residences in green environments. This possible effect of telecommuting on residential locational preferences has 
not yet been fully explored. Therefore, this paper will present an analysis of the effects of telecommuting on residential locational preferences.

\section{Data and research methods}

The WBO 2002 database has been analysed to address the questions posed in this research. WBO is a quadrennial survey among households covering all aspects of housing in the country (MVROM 2003). It is commissioned by the Ministry of Housing, Spatial Planning and the Environment (MVROM). In the 2002 version, 75,000 household were successfully interviewed. The final database includes variables related to housing situation, preferences, housing expenditures, residential mobility, and a large number of socio-cultural and socioeconomic background variables.

The WBO 2002 aims at identifying the overall residential locational preferences in the Netherlands. The survey includes the question whether the respondent worked at home in combination with a fixed working address elsewhere. Unfortunately, such details as how many hours per day or week or month the respondent worked at home, and whether or not ICTs were used for that purpose, were not asked. In this study, "telecommuting therefore has the broad meaning of working at home along with a fixed work address other than the house address". A comparable operationalization was used by Mokhtarian and Bagley (2000). The definition will certainly exaggerate the number of telecommuters, but a large share of the selected group will most likely use ICTs to communicate regularly with the employer's base. Moreover, the whole group will share the option of having relatively wide housing-location margins. All workers not belonging to the category of telecommuters as defined above are further referred to as commuters.

For telecommuting to have an impact on residential locational patterns, two conditions must hold. First, a substantial number of workers must telecommute; second, these telecommuters must have locational preferences that differ from those of commuters (Ellen and Hempsted 2002).

The frequencies of commuters and telecommuters are shown in Table 1. In the year $2002,7.3 \%$ of the total working population in the survey was engaged in some sort of telecommuting. This proportion is substantial enough to support the investigation of telecommuters' differences from commuters in their residential locational preferences. The proportion is also in line with the percentages reported in the studies on telecommuting reviewed in section 1 .

The same criterion was used for determining whether the partners of the main respondents were commuters or telecommuters. In the case of double-income households, most of the respondents who telecommute had partners that (still) commute (Table 2).

There are relatively more telecommuters who have telecommuting partners as compared to commuters as main respondent. Although the majority of the partners commute, there are also many who do not work. Furthermore, a considerable share of the telecommuters are single.

Table 1 Composition of main respondents as commuters and telecommuters

Source: (WBO survey 2002)

\begin{tabular}{lrr}
\hline Category & Frequency & Percent \\
\hline Telecommuters & 2,930 & 7.3 \\
Commuters & 37,039 & 92.7 \\
Total & 39,969 & 100.0 \\
\hline
\end{tabular}


Table 2 Composition of households: commuters and telecommuters (in \%)

Source: (WBO survey 2002)

\begin{tabular}{lccll}
\hline Main respondent & Single & Partner & & \\
\cline { 3 - 5 } & & Telecommuter & Commuter & Do not work \\
\hline Telecommuter & 22.5 & 16.2 & 43.3 & 18.0 \\
Commuter & 26.7 & 4.2 & 44.3 & 24.8 \\
Overall & 26.4 & 5.1 & 44.2 & 24.3 \\
\hline
\end{tabular}

The statistical analysis starts with descriptive analyses of the general characteristics of commuters and telecommuters. Then, the effects of telecommuting and traditional factors related to residential locational preferences are studied to find out their relative importance by applying multivariate analyses through linear regression and (binary and multinomial) logistic regression models. As discussed in section 2, the indicators with respect to residential location, commute distance, education, household composition, employment, and household net monthly income will be included as explanatory variables in the statistical analyses. Along with these traditional variables, the telecommuting status of both main respondent and partner were added to assess the effects of telecommuting on residential locational preferences.

\section{General characteristics of commuters and telecommuters}

In order to compare the main socioeconomic characteristics of commuters and telecommuters, both of them were subdivided into five age and three income groups. Low income households have a net monthly income of less than 1,500 euros; medium income households have a net monthly income of 1,500-2,500 euros; and high income households have a net monthly income of more than 2,500 euros. In general, telecommuters are older and have higher incomes (Figs. 1 and 2). There are more telecommuters in the age category of 36-65 years as compared to other age categories. The commuters are almost equally divided among the income groups distinguished. The telecommuters, however, are overrepresented in the highest income group.

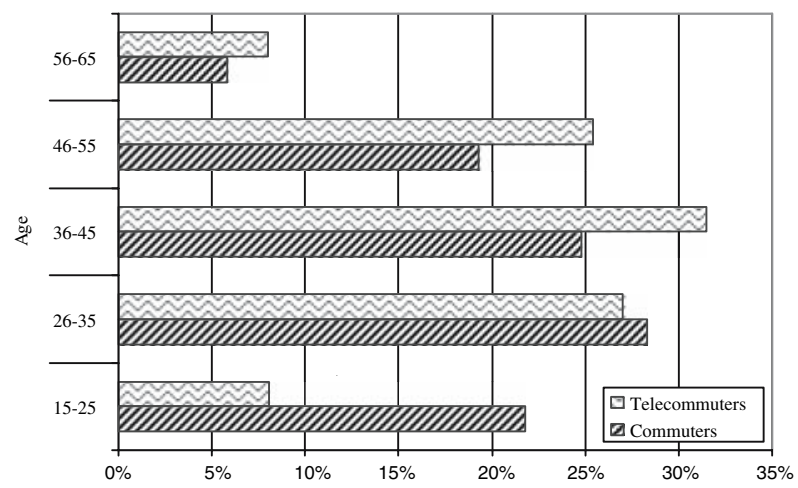

Fig. 1 Commuters and telecommuters by their age 


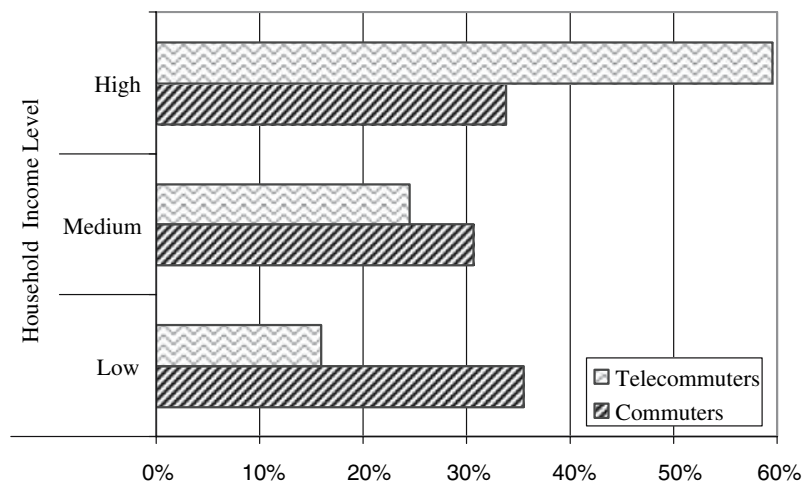

Fig. 2 Commuters and telecommuters by their monthly household income level

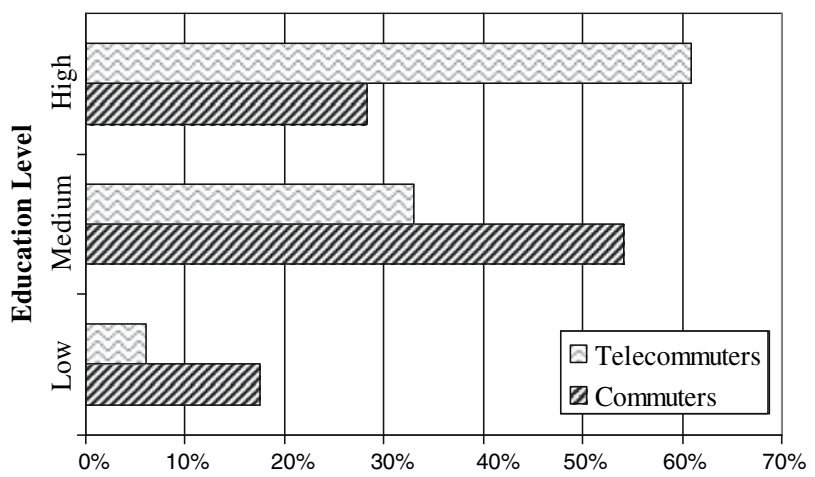

Fig. 3 Education level of commuters and telecommuters

Both commuters and telecommuters are also categorized according to their educational level. Primary education is considered as low level education, secondary or higher secondary as medium level, and vocational or university education as high level education. The educational level of both commuters and telecommuters is shown in Fig. 3. It is clear that telecommuters on average have a higher educational level than commuters. This finding confirms that telecommuting jobs require relatively high qualifications, competencies and substantial work experience, as reported by several authors (Ellen and Hempsted 2002; Goetgeluk et al. 2002; Johnston and Nolan 2002; Van Oort et al. 2003a; Willigenburg and Van Osch 2000).

\section{Factors explaining current location of residence}

As shown in Fig. 4, in 2002 both commuters and telecommuters were residing in all types of residential environment. However, the distributions of commuters and telecommuters across all residential environments were significantly different, according to both binomial and chi-square tests $(p<.001)$. The most frequent residential type of both commuters and telecommuters is the outer city area, the planned and unplanned post-war suburbs, in 


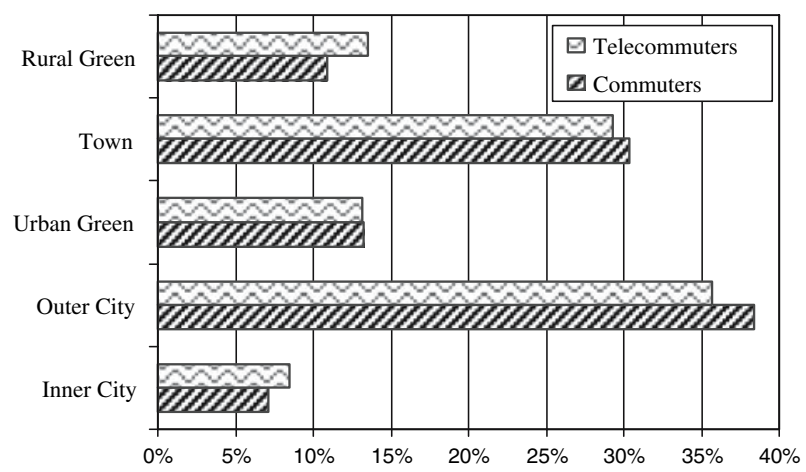

Fig. 4 Current location of residence of commuters and telecommuters



Fig. 5 Differences in current location of residences of commuters and telecommuters according to their age

regional urban centres and in rural areas. Although the differences in residential location between commuters and telecommuters are minute, in relative terms telecommuters are slightly more oriented towards living in green rural environments and inner cities than commuters. This may point at two segments of telecommuters with different residential preferences.

Broken down by age groups (Fig. 5), the general patterns of shares of residential environments for commuters and telecommuters are quite different. This finding is statistically significant according to both binomial and chi-square tests at $p<.001$. Figure 5 suggests that older telecommuters appear to be responsible for the overrepresentation in rural environments, while old age commuters account for their above-average presence in outer city environments. Furthermore, there are relatively more telecommuters residing in the inner city as compared to commuters belonging to all age groups except middle age.

Not surprisingly, a comparable picture is found when looking at differences among income subgroups in the distribution of commuters and telecommuters across residential environments. This finding is also statistically significant at $p<.001$. Figure 6 indicates that middle and higher income telecommuters are overrepresented in rural green environments, while the low and medium income ones are overrepresented in the inner city. On the other hand, low and middle income groups of commuters are overrepresented in outer city 


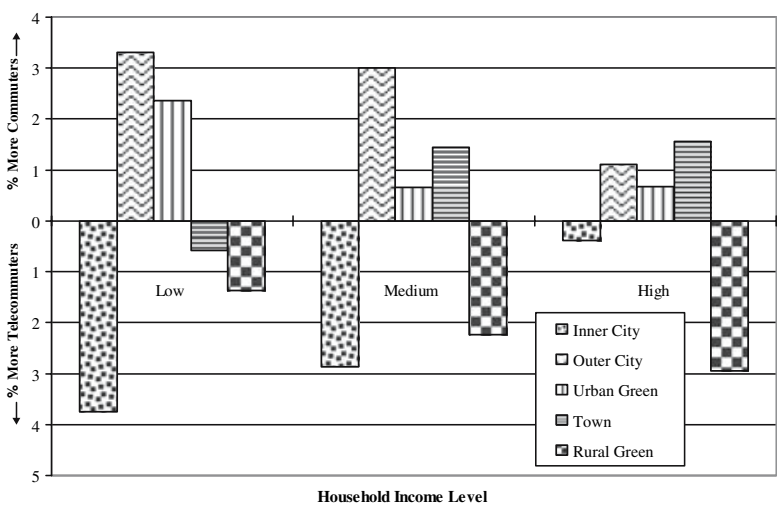

Fig. 6 Differences in current location of residences of commuters and telecommuters according to their household income level

environments. There are also an above average number of low income commuters residing in urban green environments.

In order to reveal the contribution of telecommuting, along with traditional factors (mentioned in section 3) for their current location of residence, a multinomial logistic regression model was estimated (Table 3). The dependent variable is the current location of residence. The inner city serves as the reference category, implying that effects are interpreted relative to this residential environment.

The results show that if the main respondent telecommutes, he/she is more likely to live in a rural environment as compared to the inner city. If the partner telecommutes, the household is less likely to live in the outer city, an urban green area or town, implying a larger probability to reside in rural green or inner city environments. It should be noted, however, that the causality of the relationship is uncertain. Although it is possible that a preference for telecommuting leads to a choice to live in a rural environment, it is also possible that the fact of living in a rural environment makes one decide to telecommute, in order to deal with the longer commute distance. A different type of data (longitudinal data or qualitative interviews) would be required to solve this problem.

Relative to single households without children, all household types are more likely to live in areas outside the inner city. Compared to all types of couples, single workers with children are less likely to live in towns or rural greens areas, which can be explained by the worse accessibility of schools and jobs, making it more difficult to combine work and child care tasks. As a separate factor, the presence of children leads to a larger probability of living in suburban and rural areas.

Furthermore, the analysis confirms the pattern that the youngest age groups and the medium and higher income level groups are overrepresented in the urban-type environments, while middle aged and old age people prefer to reside in more peripheral rural environments. The "green urban environments" clearly hold an intermediate position, being attractive to households with a high income and high education. This result is hardly surprising, since green urban environments are a luxury setting, having relatively low density residential districts both within and at the edges of the large and medium-sized cities.

Overall, it can be concluded that along with other traditional factors (household composition, number of children in the household, and age), telecommuting is associated with the location of residence, in the sense that telecommuters are more likely to reside in rural 


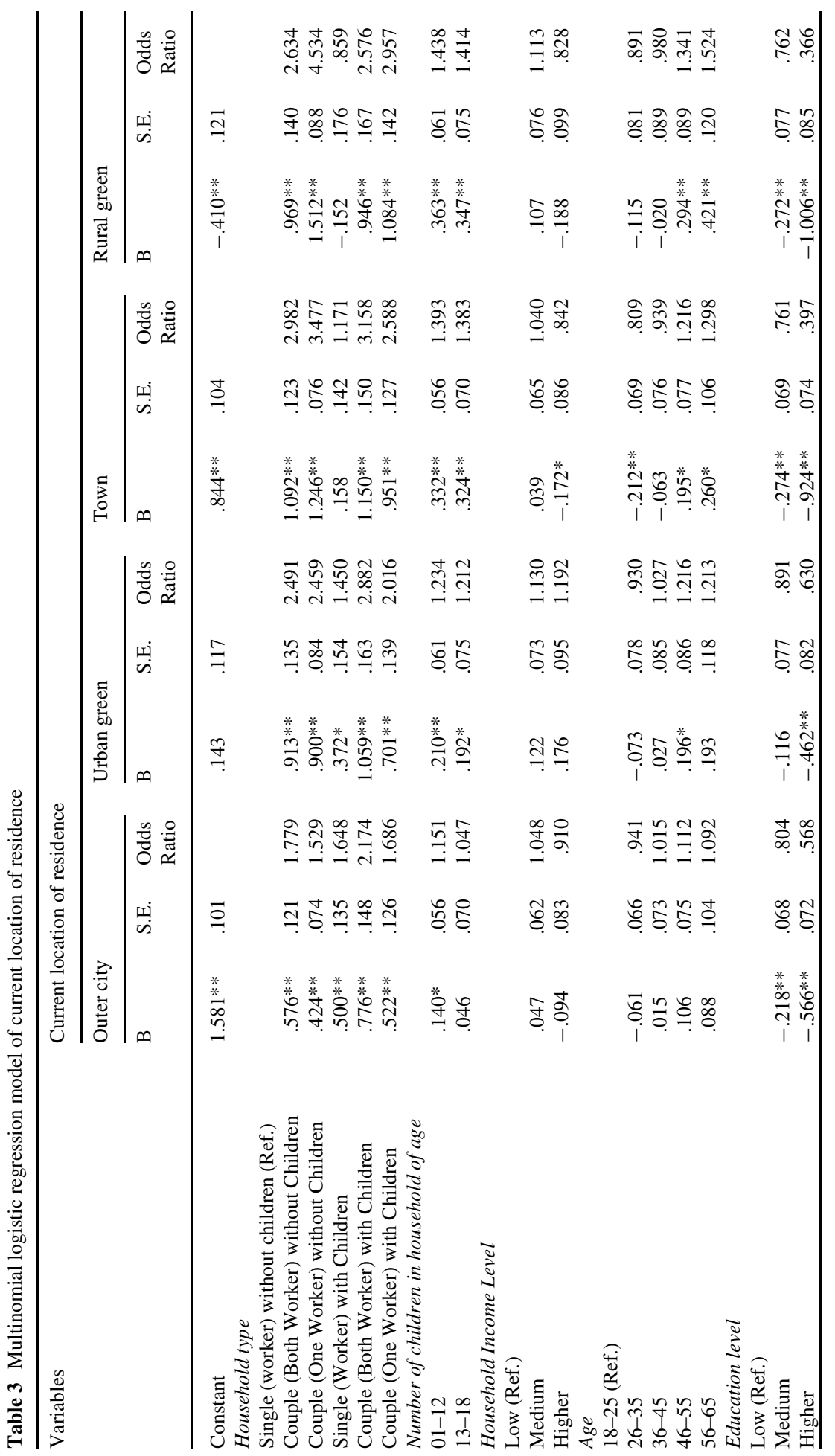




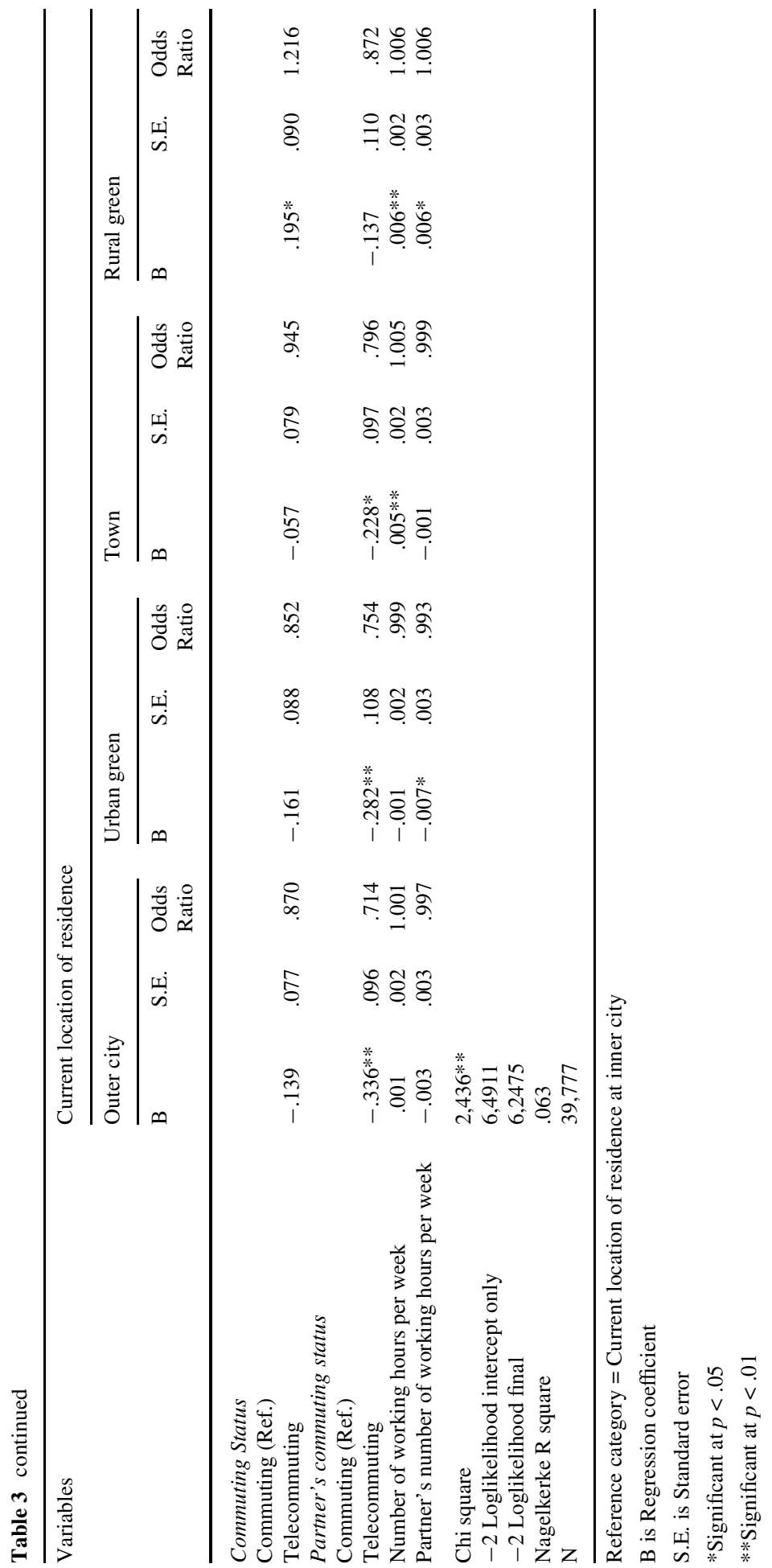


areas. The analysis does not make it clear whether telecommuters have a higher preference for rural areas or whether rural residents are more likely to adopt telecommuting.

\section{Factors affecting commuting distance}

As explained in section 1 and 2, telecommuting is expected to have major consequences for commuting practices, in particular for commuting distance and frequency. Therefore, we tested whether commuting distance is being affected by telecommuting along with traditional factors, which could influence the future residential locational preferences. To this end, a linear regression model was estimated, with commute distance as the dependent variable. We used a logarithmic transformation $(\ln (d))$ of distance, since we expect that the relationship between the explanatory variables and distance is non-linear. The coefficient of determination (R Square) is .097 , so a relatively small amount $(9.7 \%)$ of the variance in commute distance was actually explained by the variance in the independent variables. As could be expected, a positive association between this distance and telecommuting appears, confirming that telecommuters do indeed have longer commute distances. People living in rural environment are travelling a longer distance as compared to people living in urban environments. Relative to single workers without children, all types of households except single workers with children have longer commute distances. The number of children of all ages in the household has a decreasing effect on commute distance. With increasing educational and income levels, the commute distance also increases. This can be explained by the more specialized jobs held by these categories (Table 4).

The most important negative relationships relate to age categories. The commuting distance tends to decline gradually for old age categories. The respondents who work more hours per week have longer commute distances. The telecommuting status of the partner does not have a significant effect on the commute distance of the main respondent, while a higher number of working hours of the partner tends to reduce the commute distance of the main respondent. Overall, the regression analysis confirms the findings of other studies such as those by Martens et al. (1999), Mokhtarian (1998), and Van Reisen (1997) that telecommuters still commute physically as well, but with a lower frequency and a longer distance than regular commuters.

\section{Factors explaining intended change of residence}

In the WBO 2002 survey, detailed information about the intention to change residence in the coming 2 years was collected. The pre-coded answer options included: "have no intention, have intention (subdivided into: maybe, like to, yes, ready), and don't know". To keep the analysis manageable, these options were categorized into two classes: either having the intention (maybe, like to, yes, ready) to change residence or not (no intention or don't know). This dichotomization creates a binary type of variable which allows the use of a binary logistic regression model for analysing the factors (mentioned in section 3 ) related to an expressed intention to move within the next 2 years (Table 5). The chi-square value is highly significant, which means that the null hypothesis that all effects of the independent variable are zero can be rejected. The Nagelkerke R square value (.177) is moderate.

The estimation results indicate that, relative to single workers without children, one worker couples without children are more likely to relocate. Couples with children and dual income couples without children are less likely to change residence. 
Table 4 Linear regression model of commute distance

\begin{tabular}{|c|c|c|c|}
\hline \multirow[t]{2}{*}{ Variables } & \multicolumn{3}{|c|}{ LN (commute distance in $\mathrm{km}$ ) } \\
\hline & $\mathrm{B}$ & S.E. & Standardized beta \\
\hline Constant & $2.375 * *$ & .885 & \\
\hline \multicolumn{4}{|l|}{ Household type } \\
\hline \multicolumn{4}{|l|}{ Single (worker) without children (Ref.) } \\
\hline Couple (both worker) without children & $4.476^{* *}$ & .844 & .062 \\
\hline Couple (one worker) without children & $1.191 *$ & .527 & .013 \\
\hline Single (worker) with children & -1.183 & .928 & -.007 \\
\hline Couple (both worker) with children & $3.888^{* *}$ & .939 & .055 \\
\hline Couple (one worker) with children & $2.116^{* *}$ & .775 & .021 \\
\hline \multicolumn{4}{|l|}{ Number of children in household of age } \\
\hline $01-12$ & $-.722 *$ & .306 & -.020 \\
\hline $13-18$ & $-1.912 * *$ & .382 & -.035 \\
\hline \multicolumn{4}{|l|}{ Household income level } \\
\hline \multicolumn{4}{|l|}{ Low (Ref.) } \\
\hline Medium & $6.482 * *$ & .472 & .096 \\
\hline Higher & $10.384 * *$ & .601 & .161 \\
\hline \multicolumn{4}{|l|}{ Age } \\
\hline \multicolumn{4}{|l|}{$18-25$ (Ref.) } \\
\hline $26-35$ & $3.094 * *$ & .502 & .045 \\
\hline $36-45$ & $1.213^{*}$ & .536 & .017 \\
\hline $46-55$ & -1.036 & .535 & -.013 \\
\hline $56-65$ & $-3.082 * *$ & .736 & -.024 \\
\hline \multicolumn{4}{|l|}{ Education level } \\
\hline \multicolumn{4}{|l|}{ Low (Ref.) } \\
\hline Medium & $3.394 * *$ & .424 & .055 \\
\hline Higher & $10.260 * *$ & .485 & .153 \\
\hline \multicolumn{4}{|l|}{ Current location of residence } \\
\hline \multicolumn{4}{|l|}{ Inner city (Ref.) } \\
\hline Outer city & $2.037 * *$ & .599 & .032 \\
\hline Urban green & $2.347 * *$ & 684 & .026 \\
\hline Town & $5.544 * *$ & .618 & .082 \\
\hline Rural green & $7.592 * *$ & .712 & .077 \\
\hline \multicolumn{4}{|l|}{ Commuting status } \\
\hline \multicolumn{4}{|l|}{ Commuting (Ref.) } \\
\hline Telecommuting & $3.132 * *$ & .583 & .026 \\
\hline \multicolumn{4}{|l|}{ Partner's commuting status } \\
\hline \multicolumn{4}{|l|}{ Commuting (Ref.) } \\
\hline Telecommuting & .569 & .701 & .004 \\
\hline Partner's commute distance & $.131 * *$ & .007 & .107 \\
\hline Number of working hours per week & $.345 * *$ & .014 & .131 \\
\hline Partner's number of working hours per week & $-.340 * *$ & .020 & -.204 \\
\hline $\mathrm{F}$ & $178^{* *}$ & & \\
\hline $\mathrm{R}$ square & .097 & & \\
\hline Adjusted R square & .096 & & \\
\hline $\mathrm{N}$ & 39,967 & & \\
\hline
\end{tabular}

$\mathrm{B}$ is Regression coefficient

S.E. is Standard error

*Significant at $p<.05$

**Significant at $p<.01$ 
Table 5 Binary logistic regression model of intention for change of residence in coming 2 years

\begin{tabular}{|c|c|c|c|}
\hline Variables & B & S.E. & Odds ratio \\
\hline Constant & $.161^{*}$ & .068 & 1.175 \\
\hline \multicolumn{4}{|l|}{ Household type } \\
\hline \multicolumn{4}{|l|}{ Single (worker) without children (Ref.) } \\
\hline Couple (both worker) without children & $-.332 * *$ & .073 & .717 \\
\hline Couple (one worker) without children & $.187 * *$ & .040 & 1.205 \\
\hline Single (worker) with children & .078 & .071 & 1.082 \\
\hline Couple (both worker) with children & $-.509^{* *}$ & .079 & .601 \\
\hline Couple (one worker) with children & $-.125 *$ & .061 & .882 \\
\hline \multicolumn{4}{|l|}{ Number of children in household of age } \\
\hline $01-12$ & -.043 & .026 & .958 \\
\hline $13-18$ & -.020 & .033 & .980 \\
\hline \multicolumn{4}{|l|}{$\begin{array}{l}\text { Household income level } \\
\text { Low (Ref) }\end{array}$} \\
\hline $\begin{array}{l}\text { Low (Ref.) } \\
\text { Medium }\end{array}$ & $-.211 * *$ & .037 & .810 \\
\hline Higher & $-.376^{* *}$ & .049 & .687 \\
\hline \multicolumn{4}{|l|}{ Age } \\
\hline \multicolumn{4}{|l|}{ 18-25 (Ref.) } \\
\hline $26-35$ & $-.521 * *$ & .036 & .594 \\
\hline $36-45$ & $-1.128 * *$ & .041 & .324 \\
\hline $46-55$ & $-1.693^{* *}$ & .044 & 184 \\
\hline $56-65$ & $-1.996^{* *}$ & .069 & .136 \\
\hline \multicolumn{4}{|l|}{ Education level } \\
\hline \multicolumn{4}{|l|}{ Low (Ref.) } \\
\hline Medium & $.095 * *$ & .035 & 1.100 \\
\hline Higher & $.332 * *$ & .040 & 1.393 \\
\hline \multirow{2}{*}{\multicolumn{4}{|c|}{$\begin{array}{l}\text { Current location of residence } \\
\text { Inner city (Ref.) }\end{array}$}} \\
\hline Inner city (Ref.) & & & \\
\hline Outer city & -.010 & .045 & .990 \\
\hline Urban green & $-.246^{* *}$ & .052 & .782 \\
\hline Town & $-.441 * *$ & .047 & .643 \\
\hline Rural green & $-.710 * *$ & .057 & .492 \\
\hline \multicolumn{4}{|l|}{ Commuting status } \\
\hline \multicolumn{4}{|l|}{ Commuting (Ref.) } \\
\hline Telecommuting & .071 & .047 & 1.074 \\
\hline \multicolumn{4}{|l|}{ Partner's commuting status } \\
\hline \multicolumn{4}{|l|}{ Commuting (Ref.) } \\
\hline Telecommuting & .028 & .060 & 1.028 \\
\hline Commute distance & $.002 * *$ & .000 & 1.002 \\
\hline Number of working hours per week & $.006^{* *}$ & .001 & 1.006 \\
\hline Partner's commute distance & $.001^{*}$ & .001 & 1.001 \\
\hline Partner's number of working hours per week & .001 & .002 & 1.001 \\
\hline Chi-square & $5,326^{* *}$ & & \\
\hline-2 Loglikelihood at convergence level & 43,770 & & \\
\hline Nagelkerke $\mathrm{R}$ square & .177 & & \\
\hline $\mathrm{N}$ & 11,867 & & \\
\hline
\end{tabular}

Reference category $=$ No intention to change residence in coming 2 years

$\mathrm{B}$ is regression coefficient

S.E. is standard error

*Significant at $p<.05$

**Significant at $p<.01$ 
On the other hand, age, household income, number of children in the household, and currently living in a non-urban residential environment are factors that are negatively associated with a relocation intention. Respondents with higher incomes and in older age categories are less likely to change residence, whereas higher educated respondents are more likely to change residence.

Looking at residential location, it is found that households currently residing in urban green areas, towns, and rural areas are less likely to relocate. If the respondent works more hours, this increases the relocation probability. With respect to commute distance, it is found that both the main respondent's and the partner's commute distance positively affect relocation probability. But the telecommuting status, both of the respondent and of the partner, do not have a statistically significant effect on relocation probability.

Altogether, this regression confirms the importance of commute distance in relocation decisions. At the same time, telecommuting does not lead to a higher relocation probability, suggesting that telecommuting is a permanent state in which a longer commute distance is balanced against a more attractive residential area, rather than being a temporary measure to deal with a long commute in anticipation of a residential relocation.

\section{Factors explaining future residential locational preferences of commuters and telecommuters}

The last analysis was undertaken to unravel the statistical relationships of the factors explaining the preferred location of future residences for commuters and telecommuters. This task is far from straightforward, as we have to deal with small sample sizes of subgroups. Some $70 \%$ of all the main respondents (both commuters and telecommuters) had no intention to change residence in the next 2 years, leaving less than 800 cases of telecommuters in the analysis. In the previous section, it was found that telecommuting has a neutral effect on intention for change of residence. However, this does not necessarily prevent telecommuters from having different preferences once they decide to relocate. This is tested in a multinomial logistic regression model, in which the future desired location of residence was the dependent variable. The inner city area served as the reference category (Table 6).

Telecommuting status has a statistically significant association with residential locational preferences for urban environments and towns. The partner's telecommuting status does not have a significant effect. With a larger number of working hours, preference for all residential environments increases relative to the inner city.

With respect to the effect of current residential location, it is found that those planning to relocate prefer to find their new residence in the same residential environments where they are currently living, followed by spatially 'adjacent' types. For instance, those living in a town prefer to stay living in a town, with rural and urban green areas as second best options. There are no clear relationships between the household type and the preferred residential environment, except for dual income couples without children, who prefer towns or rural environments, and dual income couples with children, who prefer towns. The presence of children in the household leads to a higher preference for all residential environments as compared to the inner city.

All the age groups have preferred all residential environments. The outer city urban environment is relatively more strongly preferred by the middle age groups. The urban green and rural environment will attract relatively more middle and old aged people. Young people have a higher preference for rural environments than urban ones. Overall there is trend in all age groups to have their future residence in a rural environment, which 


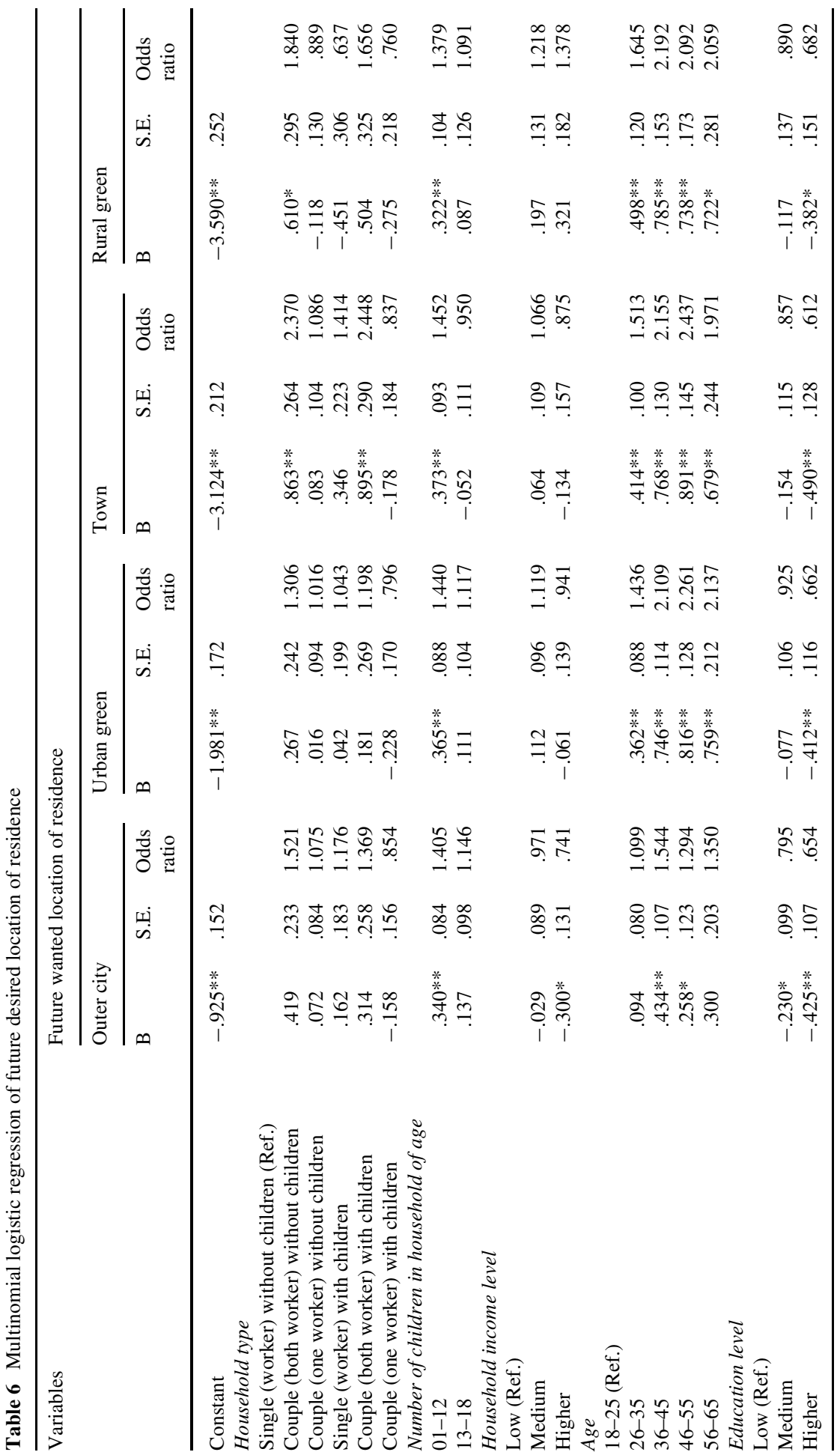




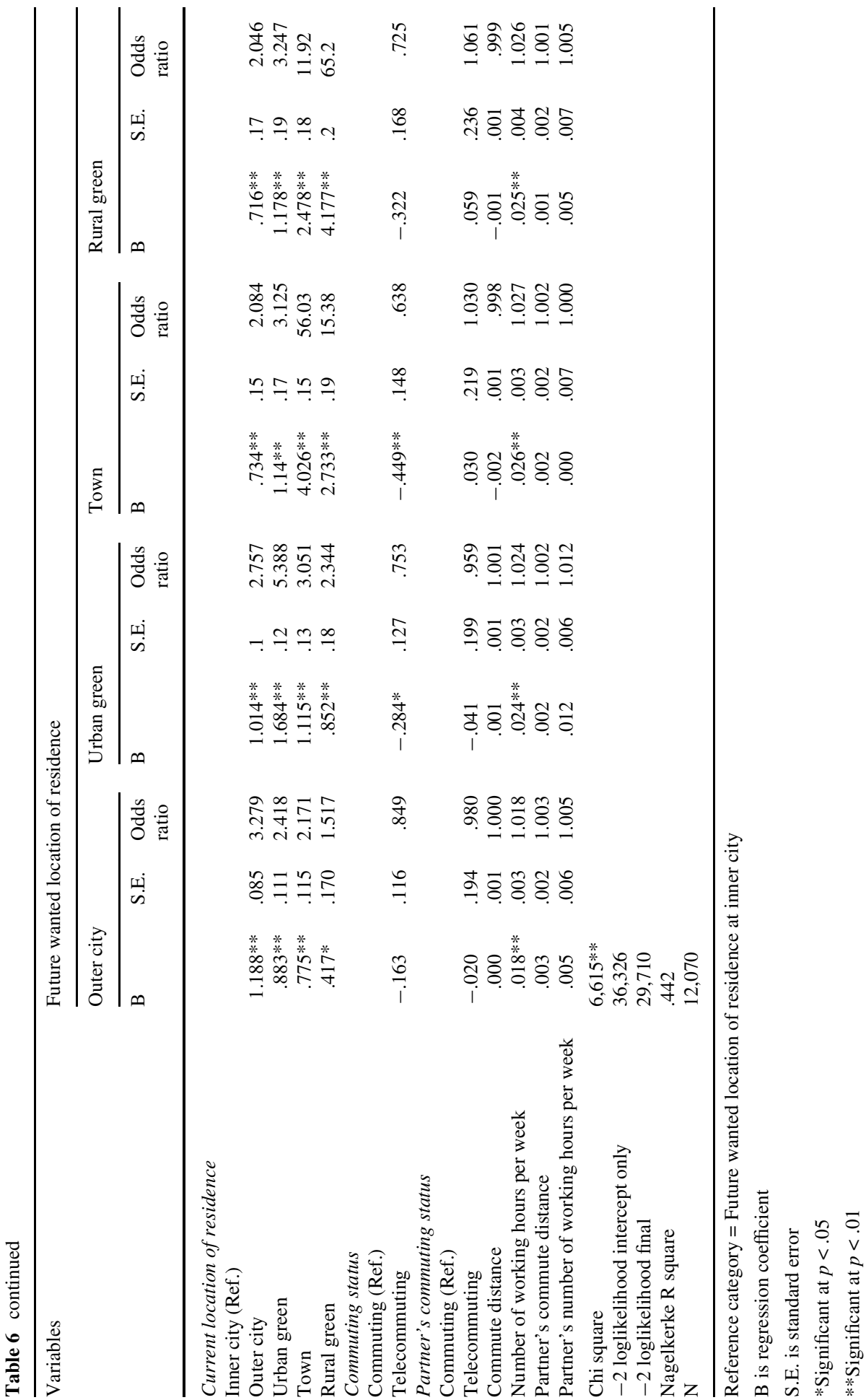


slightly increases among young age groups and decreases for middle and old age groups. In addition, highly educated people will have a higher preference for rural living environments as compared to urban ones.

On the basis of this analysis, it can be concluded that telecommuters are more likely to prefer their future residence to be located in an urban green environment or a town as compared to other living environments. This differs slightly from their current residential environments, which were more likely to be located in rural areas. Among the traditional factors, age, number of children in the household and current location of residence were the main ones affecting the future desired location of residence.

\section{Conclusions}

In this paper we have explored the potential effects of telecommuting on residential preferences and relocation decisions. A first outcome is that in the Dutch context, telecommuters also have longer commute distances than regular commuters. This implies that telecommuting leads to a different valuation of commute distance in relocation decisions, implying that a widespread adoption of telecommuting may lead to changes in residential patterns. In addition, telecommuters are not more likely to intend to change residence, suggesting that telecommuting is adopted as a rather permanent state, which allows one to overcome a longer commute and live in a more peripheral area with higher quality surroundings. Finally, an analysis of both the current and the preferred residential environment indicates that, as hypothesized, telecommuters have a higher probability than commuters to reside in more peripheral areas, such as urban green settings, towns, and rural areas.

With respect to the potential effect of telecommuting on residential patterns, it is noted that although telecommuting facilitates longer commute distances, a dramatic shift in the meaning of distance, as announced by some researchers, is not fully substantiated in this study, especially for the future preferred location of residence. Thus, traditional factors like household type, number of children in the household, and especially the stages of life cycle still play a dominant role in residential locational preferences. Along with that, the majority of the people wish to have their future residence in the same residential environment as the one in which they are residing at present. For such a short period of 2 years in the future, in which telecommuting must still become established, it needs to be considered that the majority of telecommuters have partners who commute. It is difficult to assert that, for all of them, telecommuting will result in a preferred residence in a rural environment situated far away from the existing work location and not having good transport infrastructure. Taking the trends shown for current location of residence and future preferred location of residence into consideration can lead us to expect that telecommuting in the Netherlands, along with traditional factors, will play a part in somewhat more residential locational preferences in urban green and rural environments. That expectation is already reflected in the decentralization policies.

Overall, it is noted that in the WBO 2002 survey, two groups of telecommuters could be identified. By far the largest group consists of middle and old aged, well-educated professionals belonging to middle and higher income groups and living in family households. Their current residential environment is, to an above-average degree, a rural green environment. These people are not very likely to move to another type of environment in the near future. A second important group of telecommuters comprises young professionals with a high level of education but not (yet) a high income. These people clearly prefer urban residential settings, in particular inner city environments. Since it is important to distinguish 
different segments of telecommuters with respect to their residential preferences, future analyses will focus on identifying the specific needs and preferences of these groups, for instance using cluster analyses and latent class analysis.

Acknowledgements We are grateful to the Urban and Regional Research Centre Utrecht (URU) for funding this research and to the Netherlands' Ministry of Spatial Planning, Housing and the Environment (MVROM) for providing the housing demand survey 2002 data. We are also thankful to Anne Hawkins for editing the text. Finally we would like to extend our thanks to the editorial board and two anonymous reviewers for their useful comments and suggestions on earlier versions of this article.

\section{References}

Bates, P., \& Huws, U. (2001). Modelling ework in Europe, estimates, models and forecasts from EMERGENCE Project. Brighton: The Institute for Employment Studies.

Cairncross, F. (1998). The death of distance, how the communication revolution will change our lives. London: Butler and Tanner Ltd.

Castells, M., \& Hall, P. (1994). Technopoles of the world, the making of 21st century industrial complexes. London: Routledge.

CBS (Centraal Bureau voor de Statistiek) (1995). Onderzoek Verplaatsingsgedrag. Statistics Netherlands, Heerlen/The Hague.

CBS (Centraal Bureau voor de Statistiek) (2005). De digitale economie 2005. Statistics Netherlands, Voorburg/ Heerlen.

Clark, W. A. V., \& Onaka, D. L. (1983). Life cycle and housing adjustment as an explanation of residential mobility. Urban Studies, 20, 47-57.

Couclelis, H. (1998). The new field workers. Environment and Planning B, 25(3), 321-323.

Couclelis, H. (2003). Housing and the new geography of accessibility in the information age. Open House International, 28(4), 7-13.

Dokmeci, V., \& Berkoz, L. (2000). Residential-location preferences according to demographic characteristics in Istanbul. Landscape and Urban Planning, 48, 45-55.

Ellen, I. G., \& Hempsted, K. (2002). Telecommuting and demand for urban living: A preliminary look at white-collar workers. Urban Studies, 39(4), 749-766.

Empirica (2003). Measuring the Information Society in the EU, the EU accession countries, Switzerland and the US: SIBIS Pocket Book 2002/03, Bonn.

Giuliano, G. (1998). Information technology, work patterns and intra-metropolitan location: A case study. Urban Studies, 35, 1077-1095.

Goetgeluk, R., Louw, E., \& Priemus, H. (2002). Bijlagenrapport Willen Telewerkers Anders Wonen, Een kwalitatieve studie naar de mogelijke invloed van telewerken op het tijd-ruimte budget en de woningkeuze. Delft: OTB.

Graham, S., \& Marvin, S. (2000). Urban planning and the technological future of cities. In J. O. Wheeler, Y. Aoyama, \& B. Warf (Eds.), Cities in the telecommunications age, the fracturing of geographies (pp. 71-96). London: Routledge.

Hansen, W. G. (1959). How accessibility shapes land use. Journal of American Institute of Planners, 25, 73-76.

Healy, P. (2004). The treatment of space and place in the new strategic spatial planning in Europe. International Journal of Urban and Regional Research, 28, 45-67.

Horner, M. W. (2004). Spatial dimensions of urban commuting: A review of major issues and their implications for future geographic research. The Professional Geographer, 56, 160-173.

Huws, U., \& O'Regan, S. (2001). ework in Europe, the EMERGENCE 18-country employment survey. Brighton: The Institute for Employment Studies.

Johnston, R. J., Gregory, D., \& Smith, D. M. (1994). The dictionary of human geography (3rd ed.). Oxford: Blackwell.

Johnston, P., \& Nolan, J. (2002). ework 2002, status report on new ways to work in the information society. Brussels: European Commission.

Kim, T. K., Horner, M. W., \& Marans, R. W. (2005). Life cycle and environmental factors in selecting residential job locations. Housing Studies, 20(3), 457-473.

Lamanna, R. A. (1964). Value consensus among urban residents. Journal of the American Institute of Planners, 30, 317-323.

Lindberg, E., Garvill, J., Garling, J., \& Montgomery, T. (1992). Economic and noneconomic motives for residential preferences and choices. Journal of Economic Psychology, 13(1), 39-56. 
Malecki, E. J., \& Gorman, S. P. (2001). May be the death of distance, but not the end of geography. In T. R. Leinbach, \& S. D. Brunn (Eds.), Worlds of e-commerce: Economic, geographical and social dimensions (pp. 87-108). Chichester: John Willey.

Martens, M., Wilmink, I., Korver, W., Heijma, A., Katwijk, R. V., \& Harrell, L. (1999). The mobility impact of the electronic highway. Delft: TNO.

Michaelson, W. (1977). Environmental choice, human behaviour and residential satisfaction. New York: Oxford University Press.

Mitchell, W. J. (2000). E-topia, urban life, Jim-but not as we know it. Cambridge: MIT Press.

Mohammad, R. T., Khan, A. M., \& Donald, A. (2003). Impact of telecommuting and intelligent transportation systems on residential location choice. Transportation Planning and Technology, 26(2), 171-193.

Mokhtarian, P. L. (1991). Defining telecommuting. Transportation Research Records, 1305, $273-281$.

Mokhtarian, P. L. (1998). A synthetic approach to estimating the impacts of telecommuting on travel. Urban Studies, 35(2), 215-241.

Mokhtarian, P. L., \& Bagley, B. N. (2000). Modelling employee's perceptions and proportional preferences of work locations: The regular workplace and telecommuting alternatives. Transportation Research A, 34, 223-242.

Mokhtarian, L. P., Gustavo, O. C., \& Carsten, G. (2003). Telecommuting, residential location, and commute distance travelled: Evidence from state of California employees, Available from www.uctc.net/scripts/ countdown.pl?670.pdf.

Mokhtarian, P. L., \& Salomon, I. (1997). Modelling the desire to telecommute: The importance of attitudinal factors in behaviour models. Transportation Research A, 31(1), 35-50.

Mokhtarian, P. L., \& Varma, K. V. (1998). The trade-off between trips and distance travelled in analyzing the emission impact of centre-based telecommuting. Transportation Research D, 3(6), 419-428.

MVROM (Ministerie van Volkshuisvesting, Ruimtelijke Ordening en Milieu). (2003). WoningBehoefte Onderzoek. The Hague: Ministry of Housing, Physical Planning and the Environment.

Naes, P. (2005). Accessibility, activity participation and location of activities: Exploring the links between residential location and travel behaviour. Urban Studies, 43(3), 627-652.

Nijkamp, P., Wissen, L. V., \& Rima, A. (1993). A household life cycle model for residential relocation behaviour. Socio-Economic Planning Sciences, 27(1), 35-53.

Nilles, J. (1988). Traffic reduction by telecommuting: A status review and selected bibliography. Transportation Research, 22A, 301-307.

Raspe, O., \& Van Oort, F. (2004). ICT loves agglomeration: The urban impact of ICT in the Netherlands. In Proceedings from ERSA 2004 Congress, University of Porto, Porto.

Renkow, M., \& Hoover, D. (2000). Commuting, migration and rural-urban population dynamics. Journal of Regional Science, 40(2), 261-287.

Simpson, W. (1987). Workplace location, residential location, and urban commuting. Urban Studies, 24, 119-128.

Sirgy, M. J., Grzeskowiak, S., \& Su, C. (2005). Explaining housing preferences and choice: The role of selfcongruity and functional congruity. Journal of Housing and the Built Environment, 20, 329-347.

Speare, A. Jr., Goldstein, S., \& Frey, W. H. (1975). Residential mobility, migration and metropolitan change. Cambridge: Ballinger.

Todd, P. P. (2006). Telework forum, the Netherlands, [cited February 27, 2006 2006], from http://www.telewerkforum.nl/english.html.

TWF (TeleWerk Forum). (2004). Dutch telewerk forum. The Hague: Telework Forum.

Van Der Laan, L., Van Oort, F., \& Raspe, O. (2005). Regional change of ICT using industries in the Netherlands. Tijdschrift voor Economische en Sociale Geografie, 96(5), 585-592.

Van Ommeren, J., Rietveld, P., \& Nijkamp, P. (1997). Commuting: In search of jobs and residences. Journal of Urban Economics, 42, 402-424.

Van Ommeren, J., Rietveld, P., \& Nijkamp, P. (2000). Job mobility, residential mobility and commuting: A theoretical analysis using search theory. The Annals of Regional Science, 34, 213-232.

Van Oort, F., Raspe, O., \& Snellen, D. (2003a). De Ruimtelijke Effecten van ICT, NAi Uigevers and Ruimtijk Planbureau, Rotterdam and Den Haag.

Van Oort, F., Weterings, A., \& Verlinde, H. (2003b). Residential amenities of knowledge workers and the location of ICT-firms in the Netherlands. Tijdschrift voor Economische en Sociale Geografie, 94(4), 516-523.

Van Reisen, F. (1997). Space for telecommuting: Effects of flexible labour on the land use and mobility due to changing time-space behaviour. Delft: TUD.

Willigenburg, M. M., \& Van Osch, F. R. A. (2000). Conditions for the development of new ways of working and electronic commerce in the Netherlands. Utrecht: Overmars Organisatie Adviseurs.

Wilson, M. I., Corey, K. E., Mickens, C., \& Mickens, H. P. (2001). Death of distance/rise of place: The impact of the Internet on locality and spatial organization. In Proceedings from The Internet Global Summit, The 11th Annual Internet Society Conference, Stockholm. 